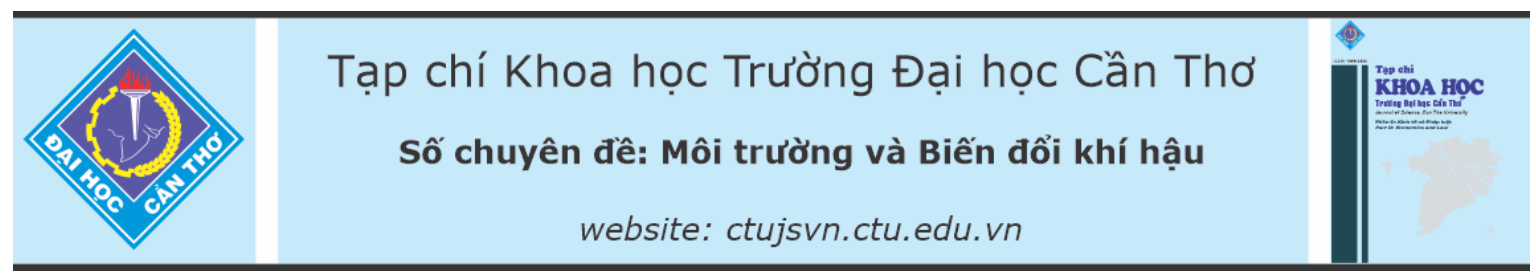

DOI:10.22144/ctu.jsi.2021.052

\title{
ĐÁNH GIÁ KẾT QUẢ THỰC HIỆN QUY HOẠCH SỬ DỤNG ĐẤT ĐAI THÀNH PHỐ CẦ THƠ GIAI ĐỘẠ 2010-2020 TỪ GÓC NHÌN CÁN BỘ QUẢN LÝ
}

Nguyễn Minh Thông ${ }^{1 *}$, Trần Thúy Phượng ${ }^{2}$ và Phan Trung Hiền ${ }^{3}$

${ }^{1}$ Ủy ban kiểm tra Thành ủy Cần Tho

${ }^{2}$ Truờng Chính trị Thành phố Cần Tho

${ }^{3}$ Khoa Luật, Truòng Đại học Cần Tho'

*Nguoòi chịu trách nhiệm về bài viết: Nguyễn Minh Thông (email: nguyenminhthongvn89@gmail.com)

\section{Thông tin chung:}

Ngày nhận bài: 12/04/2021

Ngày nhận bài sủa: 22/09/2021

Ngày duyệt đăng: 15/11/2021

Title:

Assessment the results of implementation of land use planning in Can Tho city for the period 2010-2020 from land governor's point of view

\section{Tù khóa:}

Người sử dụng đất, phân tích nhân tố khám phá, quy hoạch sư dụng đất, yếu tố ảnh hưởng

\section{Keywords:}

Exploratory factor analysis, factors affecting, land use planning, land user

\begin{abstract}
The study was conducted to determine the actual results of the land use planning of Can Tho city in the period 2010-2020 based on comparing the current state of land use and targets in two land use plan periods (20102015 and 2015-2020). Using exploratory factor analysis (EFA) model and multivariable linear regression model to identify the factors affecting land use planning in Can Tho city with 100 land governors. The results indicated that the land use in the period 2010-2020 did not achieve according to the plan. There are 5 groups of factors that positively affect the land use planning in Can Tho city from land governor's point of view including group of institutional and legal factors, group of social factors, group of economic factors, group of environmental factors and group of other factors. In the coming time, in order to make land use planning in Can Tho city more and more effective, governors need to pay attention to the following: (i) perfecting the provisions of the law on land use planning, (ii) assessing the impact of urbanization speed in forecasting land use demand in the planning process, (iii) training staff to do planning.
\end{abstract}

\section{TÓM TÁT}

Nghiên cứu sủ dụng phuơng pháp so sánh hiện trạng sư dụng đất và chỉ tiêu trong hai kỳ kể hoạch sư dụng đất (2010-2015 và 2015-2020) nhằm đánh giá kết quả thực hiện quy hoạch sư dụng đất thành phố Cần Tho giai đoạn 2010-2020. Mô hình phân tích EFA và mô hình hồi quy tuyến tính đa biến giúp xác định các yếu tố ảnh hương đến quy hoạch sư dụng đất thông qua thực hiện phỏng vấn điều tra với 100 cán bộ quản lý có chuyên môn trong lĩnh vực đất đai. Kết quả nghiên cứu cho thấy việc sử dụng đất thành phố Cần Tho giai đoạn 2010-2020 chua đạt theo kế hoach đề ra. Có 5 nhóm yếu tố ảnh hưởng tích cưc đến quy hoạch sủ dụng đất thành phố Cần Tho theo góc nhìn cán bọ quản lý gồm: nhóm yếu tố thể chế, pháp lý, nhóm yếu tố xã họi, nhóm yếu tố kinh tế, nhóm yếu tố môi trường và nhóm các yếu tố khác. Trong thời gian tới, để quy hoạch sủ dụng đất thành phố Cần Tho hiệu quả, các nhà quản lý cần quan tâm: (i) hoàn thiện các quy định của pháp luật về quy hoạch sử dụng đất, (ii) tốc độ đô thị hóa để dụ báo nhu cầu sử dụng đất, (iii) đào tạo cán bộ làm công tác quy hoạch. 


\section{1. ĐẠT VẤN ĐỀ}

Thành phố Cần Thơ đã thực hiện Quy hoạch sử dụng đất thành phố đến năm 2020 và kế hoạch sử dụng đất 05 năm kỳ đầu (2011-2015), kế hoạch sử dụng đất 05 năm kỳ cuối (2016-2020). Qua đó, nhiều công trình dự án trên địa bàn được thực hiện góp phần phát triển kinh tế xã hội của thành phố giai đoạn 2010-2020. Phấn đấu đến 2030, thành phố Cần Thơ là đô thị sinh thái, văn minh, hiện đại mang đậm bản sắc văn hoá sông nước vùng Đồng bằng sông Cửu Long; là trung tâm của vùng về dịch vụ thương mại, du lịch, logistics, công nghiệp chế biến, nông nghiệp ứng dụng công nghệ cao, giáo dục và đào tạo, y tế chuyên sâu, khoa học công nghệ, văn hoá, thể thao (Bộ Chính trị, 2020). Qua 10 năm, thực tiễn đặt ra đòi hỏi cần có nghiên cứu đánh giá kết quả thực hiện quy hoạch sử dụng đất thành phố Cần Thơ giai đoạn 2010-2020 làm cơ sở đề xuất giải pháp quy hoạch sử dụng đất thành phố trong thời gian tới (giai đoạn 2021-2030). Trong bài viết này, nghiên cứu được thực hiện với mục tiêu: (i) đánh giá kết quả thực quy hoạch sử dụng đất thành phố Cần Thơ giai đoạn 2010- 2020, (ii) xác định các yếu tố ảnh hưởng đến quy hoạch sử dụng đất thành phố Cần Thơ theo góc nhìn cán bộ quản lý, (iii) đề xuất gải pháp trong quản lý nhà nước về quy hoạch sử dụng đất.

\section{PHƯƠNG PHÁP NGHIÊN CÚU}

\subsection{Phương pháp thu thập số liệu}

Số liệu thu thập bao gồm: (i) Số liệu thứ cấp từ báo cáo kết quả thực hiện quy hoạch sử dụng đất thành phố Cần Thơ giai đoạn 2010 - 2015 và 2015 2020 làm cơ sở đánh giá những kết quả đạt được cũng như những tác động trong công tác quy hoạch sử dụng đất ở thành phố Cần Thơ; (ii) số liệu sơ cấp từ điều tra phỏng vấn 100 cán bộ quản lý chuyên môn công tác trong lĩnh vực đất đai.

Phỏng vấn KIP - Key Information Panel được sử dụng nhằm thu thập thông tin thông qua điều tra phỏng vấn những người $\mathrm{am}$ hiểu để tìm hiểu thông tin những thuận lợi và khó khăn trong thực hiện quy hoạch sử dụng đất thành phố Cần Thơ giai đoạn 2010- 2020. Hair et al. (2006) cho rằng để sử dụng phân tích nhân tố khám phá (Exploratory Factor Analysis - EFA), kích thước mẫu tối thiểu phải là 50 , tốt hơn là 100 và tỷ lệ quan sát/biến đo lường là 5:1. Trong nghiên cứu này, dự kiến có 17 biến đo lường ứng với 85 quan sát tối thiểu, nghiên cứu đã thực hiện 100 mẫu khảo sát đối với cán bộ quản lý chuyên môn công tác trong lĩnh vực đất đai.

Thang đo Likert 5 cấp độ được sử dụng để thiết kế bản câu hỏi về đo lường mức độ ảnh hưởng của các yếu tố ảnh hưởng quy hoạch sử dụng đất thành phố Cần Thơ, trong đó $1=$ Rất không đồng ý, $2=$ Không đồng ý, $3=$ Trung hòa (Phân vân), 4 = Đồng ý, và $5=$ Rất đồng ý (Likert, 1932). Người trả lời được yêu cầu chỉ chọn một phương án cho mỗi câu hỏi. Dữ liệu sơ cấp sau khi thu thập được tổng hợp bằng Excel và sử dụng SPSS phân tích.

\subsection{Phương pháp phân tích số liệu}

Phương pháp so sánh được sử dụng trong đánh giá kết quả thực hiện quy hoạch sử dụng đất thành phố Cần Thơ giai đoạn 2010-2020. Thông qua hiện trạng sử dụng đất 2015 và 2020 so sánh với các chỉ tiêu trong kế hoạch sử dụng đất kỳ đầu 2010-2015 và kỳ cuối 2015-2020.

Phurơng pháp phân tích nhân tố khám phá được sử dụng để xác định các yếu tố ảnh hưởng đến quy hoạch sử dụng đất theo góc nhìn cán bộ chuyên môn công tác trong lĩnh vực quản lý đất đai. Các yếu tố được kiểm định giá trị thang đo, thực hiện sau khi đánh giá độ tin cậy của thang đo bằng hệ số Cronbach's Alpha và loại đi các biến không đảm bảo độ tin cậy (Cronbach, 1951). Giá trị alpha tối đa 0,90 đã được đề xuất (Streiner, 2003). Dữ liệu sẽ được chấp nhận khi: (i) Tổng tương quan $>0,3$ (Nunnally \& Bernstein, 1994; Hair et al., 1998), (ii) KMO (Kaiser-Meyer-Olkin) nằm trong khoảng 0,5-1, (iii) Kiểm định Barlett's với mức ý nghĩa (Sig. $<0,05)$ để đảm bảo các yếu tố có mối tương quan với nhau trong tổng thể, (iv) Hệ số Eigenvalue có giá trị $>1$ để đảm bảo các nhóm yếu tố có sự khác biệt, (v) Tổng phương sai giải thích: Thang đo chỉ được chấp nhận khi tổng phương sai giải thích (Total variance explained) $>50 \%$.

Mô hình hồi quy đa biến được xây dựng để xác định hệ số mức độ ảnh hưởng của các yếu tố đối với quy hoạch sử dụng đất đai. Theo Bliss (1934), mô hình hồi quy gồm biến phụ thuộc và biến giải thích như sau:

$$
Y_{i}^{*}=\beta_{0}+\sum_{j=1}^{k} \beta_{j} X_{i j}+u_{i}
$$

Trong đó $Y_{i}^{*}$ chưa biết, được gọi là biến ẩn. Trong nghiên cứu này, nhằm xác định các yếu tố ảnh hưởng đến việc thực hiện quy hoạch sử dụng đất, mô hình được thiết lập như sau:

$$
Y=B_{0}+B_{1} X_{1}+B_{2} X_{2}+B_{3} X_{3}+\ldots
$$

Trong đó: đất

Y là biến phụ thuộc thể hiện quy hoạch sử dụng ất 
X là biến độc lập thể hiện các yếu tố ảnh hưởng đến việc thực hiện quy hoạch sử dụng đất

B là các tham số hồi quy

\section{KẾT QUẢ VÀ THẢO LUẬN}

\subsection{Kết quả thực hiện quy hoạch sử dụng đất thành phố Cần Thơ giai đoạn 2010- 2020}

Thành phố đã thực hiện quy hoạch sử dụng đất 2010-2020 bằng việc phân kỳ kế hoạch sử dụng đất thành phố thành 02 kỳ, kỳ đầu (2010-2015) và kỳ cuối (2015-2020). Quy hoạch sử dụng đất đai thành phố Cần Thơ đến năm 2020 và kế hoạch sử dụng đất kỳ đầu (2010-2015) được chính phủ phê duyệt theo Nghị quyết số 57/NQ-CP ngày 04/5/2013; kế hoạch sử dụng đất kỳ cuối (2016-2020) được chính phủ phê duyệt theo Nghị quyết số 52/NQ-CP ngày 10/5/2018. Căn cứ vào kế hoạch sử dụng đất cấp thành phố, quận/huyện xây dựng kế hoạch sử dụng đất hằng năm cấp quận/huyện, đây là căn cứ để chuyển mục đích sử dụng đất, giao đất, cho thuê đất (Khoản 1, Điều 52, Luật đất đai năm 2013). Nghiên cứu đã so sánh hiện trạng sử dụng đất các năm và hai kỳ kế hoạch sử dụng đất (Bảng 1 ) để đánh giá kết quả thực hiện quy hoạch sử dụng đất thành phố Cần Thơ giai đoạn 2010-2020 thông qua chỉ tiêu sử dụng từng loại đất.

Bảng 1. So sánh hiện trạng sử dụng đất và 02 kỳ kế hoạch sử dụng đất 2010-2020

\begin{tabular}{|c|c|c|c|c|c|c|c|}
\hline Nhóm đất & 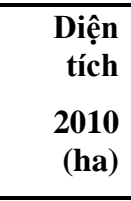 & $\begin{array}{r}\text { Diện tích } \\
\text { KHSDĐ } \\
2010- \\
\text { 2015(ha) } \\
\end{array}$ & $\begin{array}{r}\begin{array}{r}\text { Diện } \\
\text { tích }\end{array} \\
2015 \text { (ha) }\end{array}$ & $\begin{array}{r}\text { Tăng(+) } \\
\text { Giảm(-) } \\
\text { so với kỳ } \\
\text { đầu } \\
\end{array}$ & $\begin{array}{r}\text { Diện tích } \\
\text { KHSDĐ } \\
2015- \\
2020(\text { ha) } \\
\end{array}$ & $\begin{array}{r}\text { Diện } \\
\text { tích } \\
2020 \\
\text { (ha) }\end{array}$ & $\begin{array}{r}\text { Tăng(+) } \\
\text { Giảm(-) } \\
\text { so với kỳ } \\
\text { cuối }\end{array}$ \\
\hline ất $n$ & $\overline{1}$ & 110.706 & & +4.714 & 109.690 & 114.308 & +4.618 \\
\hline UA) & & & & & & 755 & 225 \\
\hline +Đất trồng cây lâu năm (CLN) & 20.683 & 21 & 23.079 & + & 29.242 & 30.793 & +1.551 \\
\hline $\begin{array}{l}\text { +Đât nuôi trông thuỷ sản } \\
\text { (NTS) }\end{array}$ & 1.560 & 1.433 & 2.458 & +1.025 & 1.500 & 2.799 & +1.299 \\
\hline $\begin{array}{l}\text { + Các loại đất khác thuộc } \\
\text { nhóm đất nông nghiệp }\end{array}$ & 1.45 & .822 & 1.875 & -3.721 & 2.418 & 1.961 & -457 \\
\hline Đất phi nông nghiệp (PNN) & 25.378 & 30.057 & 3.390 & -1667 & 3 & 29.712 & -4.494 \\
\hline +Đất khu công nghiệp (SKK) & 538 & 1.797 & 391 & -1.406 & 2.350 & 475 & -1.875 \\
\hline $\begin{array}{l}\text { +Đất thương mại, dịch vụ } \\
\text { (TMD) }\end{array}$ & 143 & 2 & 15 & $-\varepsilon$ & 319 & 407 & +88 \\
\hline +Đất ở tại đô thị (ODT) & 3.859 & 5.171 & 4.609 & -562 & 5.768 & 5.195 & -573 \\
\hline $\begin{array}{l}\text { + Các loại đất khác thuộc } \\
\text { nhóm đất phi nông nghiệp }\end{array}$ & 20.838 & 2.8 & 23.240 & + & 25.769 & 535 & -2.134 \\
\hline Đất chưa sử dụng (CSD) & 197 & 132 & 86 & -46 & 0 & 20 & -20 \\
\hline Tổng & 0.895 & 140.895 & 143.896 & 3.001 & 143.896 & 144.040 & 144 \\
\hline
\end{tabular}

Nguồn: Sở Tài nguyên và Môi trường thành phố Cần Tho, 2020.

Kết quả so sánh hiện trạng sử dụng đất và hai kỳ kế hoạch sử dụng đất qua Bảng 1 cho thấy:

Đối với nhóm đất nông nghiệp: Diện tích nhóm đất nông nghiệp năm 2010 là 115.320 ha, kế hoạch sử dụng đất đến năm 2015 giảm còn 110.706 ha và năm 2020 giảm còn 109.690 ha. Tuy nhiên, hiện trạng đến năm 2020 là 114.308 ha, cao hơn kế hoạch 4.618 ha. Trong đó, diện tích đất trồng lúa năm 2010 là 91.627 ha, kế hoạch đến năm 2015 giảm còn 83.163 ha và năm 2020 giảm còn 76.530 ha. Tuy nhiên, đến năm 2020, diện tích đất trồng lúa là 78.755 ha, cao hơn kế hoạch 2.225 ha. Diện tích đất trồng cây lâu năm năm 2010 là 20.683 ha, kế hoạch sử dụng đất đến năm 2015 tăng 21.228 ha và năm 2020 tăng 29.242 ha. Hiện trạng đến năm 2020 cho thấy diện tích đất trồng cây lâu năm cao hơn kế hoạch 1.551 ha. Diện tích đất nuôi trồng thủy sản năm 2010 là 1.560 ha, kế hoạch đến năm 2015 giảm là 1.440 ha và kế hoạch đến 2020 là 1.500 ha. Tuy nhiên, hiện trạng đến năm 2020 tăng 2.799 ha, cao hơn kế hoạch 1.299 ha. Tỷ lệ diện tích đất trồng lúa so với tổng diện tích tự nhiên năm 2020 là 54,67\%. Nhìn chung, xu hướng diện tích đất trồng lúa giảm, diện tích đất trồng cây lâu năm và diện tích đất nuôi trồng thủy sản tăng nhưng vẫn chưa đạt so với kế hoạch đặt ra.

Đối với nhóm đất phi nông nghiệp: Diện tích đất phi nông nghiệp năm 2010 là 25.378 ha, kế hoạch sử dụng đến năm 2015 tăng lên 30.057 ha và năm 2020 tăng lên 34.206 ha. Tuy nhiên, hiện trạng đến năm 2020 là 29.712 ha, thấp hơn kế hoạch 4.494 ha. Trong đó, diện tích đất khu công nghiệp năm 2010 
là 538 ha, kế hoạch đến năm 2015 tăng 1.797 ha, kế hoạch đến năm 2020 tăng 2.350 ha. Tuy nhiên, đến năm 2020, diện tích khu công nghiệp là 475 ha, thấp hơn kế hoạch 1.875 ha. Diện tích đất thương mại dịch vụ năm 2010 là 143 ha, kế hoạch sử dụng đất đến năm 2015 tăng 230 ha, kế hoạch đến năm 2020 tăng 319 ha. Hiện trạng đến năm 2020, diện tích đất thương mại dịch vụ cao hơn kế hoạch 88 ha. Diện tích đất ở đô thị năm 2010 là 3.859 ha, kế hoạch đển năm 2015 tăng là 5.171 ha và năm 2020 là 5.768 ha. Tuy nhiên, hiện trạng diện tích đất ở đô thị đến năm 2020 tăng 5.195 ha, thấp hơn kế hoạch 573 ha. Nhìn chung, xu hướng diện tích đất ở đô thị và đất thương mại dịch vụ tăng nhanh, diện tích đất khu công nghiệp tuy có tăng nhưng vẫn thấp hơn nhiều so với kể hoạch đặt ra.

Đối với nhóm đất chưa sủ dụng: Diện tích nhóm đất chưa sử dụng năm 2010 là 197 ha, kế hoạch đến năm 2015 giảm còn 132 ha, kế hoạch đến năm 2020 giảm còn 0 ha (nghĩa là kế hoạch đến năm 2020 sẽ đưa 86 ha đất chưa sử dụng năm 2015 vào sử dụng $100 \%$ ). Tuy nhiên, hiện trạng năm 2020 là vẫn còn 20 ha đất chưa sử dụng.

Kết quả so sánh giữa hiện trạng sử dụng nhóm đất chính và kế hoạch sử dụng đất theo quy hoạch được duyệt cho thấy việc sử dụng đất chưa đạt theo kế hoạch đề ra trong việc phân kỳ thực hiện quy hoạch sử dụng đất. Diện tích nhóm đất nông nghiệp xu hướng giảm, năm 2020 giảm 1.111,01 ha so với năm 2015 và giảm 1.011,1 ha so với năm 2010. Diện tích nhóm đất phi nông nghiệp có xu hướng tăng, năm 2020 tăng 1.322 ha so với 2015 và tăng $4.344,02$ ha so với 2010 . Diện tích đất chưa sử dụng có xu hướng giảm, năm 2020 giảm 66 ha so với năm 2015 và giảm 176,56 ha so với năm 2010. Nhìn chung, xu hướng biến động đất đai thành phố Cần Thơ giai đoạn 2010-2020 chuyển dịch theo hướng giảm diện tích nhóm đất nông nghiệp và nhóm đất chưa sử dụng, tăng dần diện tích nhóm đất phi nông nghiệp. Tuy nhiên, cơ cấu đất nông nghiệp hiện nay vẫn chiếm tỷ trọng cao gần $80 \%$ diện tích tự nhiên.

\subsection{Các yếu tố được đề xuất tham gia mô hình EFA và mô hình hồi quy}

Có nhiều yếu tố ảnh hưởng đến quy hoạch sử dụng đất kế thừa từ các nghiên cứu trước và ý kiến chuyên gia. Theo Lương Văn Hinh và ctv. (2003, trích dẫn bởi Lê Anh Tuấn \& Võ Quang Minh, 2015), các yếu tố về điều kiện tự nhiên, kinh tế xã hội tác động mạnh mẽ đến quy hoạch sử dụng đất. Lê Anh Tuấn và Võ Quang Minh (2015) xác định được 8 yếu tố (tái định cư cho người bị thu hồi đất; số liệu điều tra, thu thập; khí hậu, thời tiết; đào tạo nghề, việc làm; khả năng nguồn vốn; vị trí; mục tiêu lập quy hoạch và yếu tố thị trường, nhu cầu phát triển của địa phương) tác động chủ đạo đến hiệu quả quy hoạch sử dụng đất đai. Nghiên cứu đã kế thừa kết quả các nghiên cứu khác, đồng thời bổ sung và điều chỉnh một số nhóm yếu tố được các chuyên gia cho rằng phù hợp với đặc trưng của thành phố Cần Thơ. Có 5 nhân tố độc lập với 17 biến quan sát được chọn lựa để nghiên cứu (Bảng 2).

Bảng 2. Nhân tố ảnh hưởng đến quy hoạch sử dụng đất đai ở thành phố Cần Thơ

\begin{tabular}{|c|c|c|}
\hline Nhóm yếu tố & \multicolumn{2}{|c|}{ Ký hiệu Các tiêu chí đánh giá } \\
\hline \multirow[t]{3}{*}{ Kinh tế (KT) } & KT1 & $\begin{array}{l}\text { Nguồn kinh phí chi cho quy hoạch sử dụng đất (lập quy hoạch, triển khai quy hoạch, } \\
\text { điều chỉnh quy hoạch) }\end{array}$ \\
\hline & KT2 & Tăng trưởng kinh tế \\
\hline & KT3 & Cơ cấu kinh tế \\
\hline \multirow{4}{*}{ Xã hội (XH) } & XH1 & Đặc điểm nhân khẩu học của cư dân (dân số, trình độ dân trí, sinh kế, thu nhập) \\
\hline & $\mathrm{XH} 2$ & Sự đồng thuận xã hội \\
\hline & XH3 & Tốc độ đô thị hóa \\
\hline & $\mathrm{XH} 4$ & Văn hóa - lịch sử, phong tục, tập quán \\
\hline \multirow{3}{*}{$\begin{array}{l}\text { Môi trường } \\
\text { (MT) }\end{array}$} & MT1 & Điều kiện tự nhiên (khí hậu, môi trường, tài nguyên, khoáng sản) \\
\hline & MT2 & Vị trí địa lý \\
\hline & MT3 & Biến đổi khí hậu \\
\hline \multirow{4}{*}{$\begin{array}{l}\text { Thể chế, pháp } \\
\text { lý (PL) }\end{array}$} & PL1 & Các quy định của pháp luật về quy hoạch sử dụng đất \\
\hline & PL2 & Công tác kiểm tra, giám sát việc triển khai thực hiện quy hoạch đã được phê duyệt \\
\hline & PL3 & Sự đồng bộ giữa các quy hoạch \\
\hline & PL4 & $\begin{array}{l}\text { Các quy định, tiêu chí về bảo vệ môi trường và phát triển bền vững trong công tác quy } \\
\text { hoạch sử dụng đất }\end{array}$ \\
\hline \multirow[t]{3}{*}{ Khác $(\mathrm{K})$} & K1 & $\begin{array}{l}\text { Năng lực cán bộ (cán bộ tham mưu, cán bộ lãnh đạo, quản lý) phục vụ công tác quy } \\
\text { hoạch sử dụng đất }\end{array}$ \\
\hline & $\mathrm{K} 2$ & Tầm nhìn và định hướng phát triển \\
\hline & K3 & Kinh nghiệm và sự kế thừa từ các kỳ quy hoạch trước \\
\hline
\end{tabular}




\subsection{Kết quả phân tích nhân tố khám phá EFA và mô hình hồi quy tuyến tính đa biến}

\subsubsection{Kiểm tra độ tin cậy Cronbach's Alpha}

Theo Nunnally and Bernstein (1994) và Hair et al. (1998), để dữ liệu đảm bảo độ tin cậy khi phân tích thì phải thỏa điều kiện hệ số Cronbach's Alpha nằm trong khoảng $0,6-0,95$ và có hệ số tương quan biến tổng (Corrected Item-Rest Correlation) lớn hơn 0,3 . Kết quả kiểm tra độ tin cậy thang đo các biến độc lập được trình bày ở Bảng 3 .

\section{Bảng 3. Kết quả kiểm định độ tin cậy thang đo biến độc lập}

\begin{tabular}{|c|c|c|c|}
\hline Ký hiệu & Các tiêu chí đánh giá & $\begin{array}{r}\text { Hệ số } \\
\text { tương } \\
\text { quan với } \\
\text { biến tổng } \\
\end{array}$ & $\begin{array}{r}\text { Alpha } \\
\text { nếu loại } \\
\text { mộ̂t } \\
\text { biến } \\
\end{array}$ \\
\hline & Nhóm biến KT & & 0,728 \\
\hline KT1 & $\begin{array}{l}\text { Nguồn kinh phí chi cho quy hoạch sử dụng đất (lập quy hoạch, triến khai } \\
\text { quy hoạch, điều chỉnh quy hoạch) }\end{array}$ & 0,556 & 0,635 \\
\hline KT2 & Tăng trưởng kinh tế & 0,610 & 0,565 \\
\hline \multirow[t]{2}{*}{ KT3 } & Cơ cấu kinh tế & 0,491 & 0,708 \\
\hline & Nhóm biến XH & & $\mathbf{0 , 7 8 8}$ \\
\hline XH1 & $\begin{array}{l}\text { Đặc điểm nhân khấu học của cư dân (dân số, trình độ dân trí, sinh kế, } \\
\text { thu nhập) }\end{array}$ & 0,586 & 0,743 \\
\hline XH2 & Sự đồng thuận xã hội & 0,533 & 0,771 \\
\hline XH3 & Tốc độ đô thị hóa & 0,658 & 0,708 \\
\hline XH4 & $\begin{array}{l}\text { Văn hóa - lịch sử, phong tục, tập quán } \\
\text { Nhóm biến MT }\end{array}$ & 0,625 & 0,725 \\
\hline MT1 & $\begin{array}{l}\text { Nhom bien } \mathrm{MT} \\
\text { Điều kiện tự nhiên (khí hậu, }\end{array}$ & 0,594 & $\begin{array}{l}\mathbf{0 , 7 4 5} \\
0,635\end{array}$ \\
\hline MT2 & Vị trí địa lý & 0,622 & 0,617 \\
\hline \multirow[t]{2}{*}{ MT3 } & Biến đổi khí hậu & 0,513 & 0,729 \\
\hline & Nhóm biến PL & & 0,784 \\
\hline PL1 & Các quy định của pháp luật về quy & 0,712 & 0,678 \\
\hline PL2 & $\begin{array}{l}\text { Công tác kiểm tra, giám sát việc triển khai thực hiện quy hoạch đã được } \\
\text { phê duyệt }\end{array}$ & 0,552 & 0,750 \\
\hline PL3 & Sự đồng bộ giữa các quy hoạch & 0,566 & 0,743 \\
\hline \multirow[t]{2}{*}{ PL4 } & $\begin{array}{l}\text { Các quy định, tiêu chí về bảo vệ môi trường và phát triển bền vững trong } \\
\text { công tác quy hoạch sử dụng đât }\end{array}$ & 0,554 & 0,754 \\
\hline & Nhóm nhân tố $K$ & & 0,825 \\
\hline K1 & $\begin{array}{l}\text { Năng lực cán bộ (cán bộ tham mưu, cán bộ lãnh đạo, quản lý) phục vụ } \\
\text { công tác quy hoạch sử dụng đất }\end{array}$ & 0,726 & 0,711 \\
\hline K2 & Tầm nhìn và định hướng phát triển & 0,708 & 0,731 \\
\hline K3 & Kinh nghiệm và sự kế thừa từ các kỳ quy hoạch trước & 0,615 & 0,821 \\
\hline
\end{tabular}

Qua Bảng 3, các biến độc lập đều có hệ số Cronbach's Alpha nằm trong khoảng $0,6-0,95$ và có hệ số tương quan biến tổng lớn hơn 0,3 . Điều này chứng tỏ dữ liệu đảm bảo độ tin cậy để tiếp tục phân tích thêm.

\subsubsection{Phân tích nhân tố khám phá EFA}

Kết quả phân tích mô hình nghiên cứu (Bảng 4) cho thấy các hệ số tải nhân tố đều lớn hơn 0,3 . Các nhân tố trong Bảng 4 là phù hợp và được sử dụng cho mô hình hồi quy đa biến phân tích các nhân tố ảnh hưởng đến quy hoạch sử dụng đất đai cho phát triển bền vững đối với góc nhìn của cán bộ chuyên môn. 
Bảng 4. Kiểm định Kaiser-Meyer-Olkin (KMO) và Bartlett's Test

\begin{tabular}{|c|c|c|c|c|c|c|}
\hline \multirow{2}{*}{ Biến quan sát } & \multicolumn{6}{|c|}{ Thành phần } \\
\hline & $\mathbf{1}$ & 2 & 3 & 4 & 5 & \\
\hline$\overline{\text { PL1 }}$ & 0,846 & & & & & \\
\hline PL2 & 0,766 & & & & & \\
\hline PL3 & 0,764 & & & & & \\
\hline PL4 & 0,737 & & & & & \\
\hline XH3 & & 0,817 & & & & \\
\hline XH4 & & 0,789 & & & & \\
\hline XH1 & & 0,759 & & & & \\
\hline $\mathrm{XH} 2$ & & 0,745 & & & & \\
\hline K1 & & & 0,891 & & & \\
\hline $\mathrm{K} 2$ & & & 0,882 & & & \\
\hline K3 & & & 0,785 & & & \\
\hline MT2 & & & & 0,832 & & \\
\hline MT1 & & & & 0,828 & & \\
\hline MT3 & & & & 0,758 & & \\
\hline KT2 & & & & & & 0,832 \\
\hline KT1 & & & & & & 0,805 \\
\hline KT3 & & & & & & 0,765 \\
\hline Hệ số Eigenvalue & 2,977 & 2,735 & 2,128 & 1,891 & & 1,654 \\
\hline Phương sai giải thích & 17,514 & 12,515 & 16,087 & 11,124 & & 9,731 \\
\hline Kaiser-Meyer-Olkin & & & & & & 0,645 \\
\hline Bartlett's Test & & & & & & 0,000 \\
\hline
\end{tabular}

Qua Bảng 4, trị số KMO là 0,645 thỏa điều kiện $\mathrm{KMO}$ nằm trong khoảng $0,5-1$. Điều này cho thấy các yếu tố đề xuất thích hợp để thực hiện phân tích nhân tố EFA. Kết quả kiểm định Barlett's với mức ý nghĩa 0,000 thỏa điều kiện $($ sig. $<0,05)$, điều này đảm bảo các yếu tố có mối tương quan với nhau trong tổng thể. Hệ số Eigenvalue của mỗi nhóm có giá trị lớn hơn 1 , điều này đảm bảo các nhóm yếu tố có sự khác biệt. Tổng phương sai giải thích (total variance explained) lớn hơn $50 \%$, do vậy thang đo các biến được chấp nhận.

Kết quả phân tích ma trận hệ số điểm thành phần trình bày (Bảng 5$)$. Dựa vào ma trận hệ số điểm từng thành phần, ta xác định mức độ ảnh hưởng từng biến quan sát (ảnh hưởng mạnh hay yếu, cùng chiều hay ngược chiều) đối với từng nhân tố.

Bảng 5. Ma trận hệ số điểm thành phần theo góc nhìn cán bộ chuyên môn

\begin{tabular}{|c|c|c|c|c|c|}
\hline \multirow{2}{*}{ Biến quan sát } & \multicolumn{5}{|c|}{ Nhân tố } \\
\hline & 1 & 2 & 3 & 4 & 5 \\
\hline KT1 & & & & & 0,407 \\
\hline KT2 & & & & & 0,422 \\
\hline KT3 & & & & & 0,391 \\
\hline XH1 & & 0,309 & & & \\
\hline $\mathrm{XH} 2$ & & 0,321 & & & \\
\hline XH3 & & 0,332 & & & \\
\hline XH4 & & 0,320 & & & \\
\hline MT1 & & & & 0,401 & \\
\hline MT2 & & & & 0,405 & \\
\hline MT3 & & & & 0,377 & \\
\hline PL1 & 0,329 & & & & \\
\hline PL2 & 0,318 & & & & \\
\hline PL3 & 0,315 & & & & \\
\hline PL4 & 0,295 & & & & \\
\hline $\mathrm{K} 1$ & & & & & \\
\hline K2 & & & & & \\
\hline K3 & & & 0,343 & & \\
\hline
\end{tabular}


Qua Bảng 5, các phương trình nhân tố được thiết lập cụ thể cho từng nhóm yếu tố như sau:

- Nhóm nhân tố KT có phương trình:

$\mathrm{KT}=0,407 \mathrm{KT} 1+0,422 \mathrm{KT} 2+$

\section{$0,391 \mathrm{KT} 3$}

Nhóm nhân tố KT chịu ảnh hưởng bởi 3 biến quan sát (nguồn kinh phí chi cho quy hoạch sử dụng đất, tăng trưởng kinh tế, cơ cấu kinh tế). Trong đó, nhóm yểu tố KT chịu ảnh hưởng mạnh nhất bởi biến KT2 (nguồn kinh phí chi cho quy hoạch sử dụng đất) do có hệ số điểm nhân tố lớn nhất 0,422 và chịu ảnh hưởng ít nhất bởi biến KT3 (cơ cấu kinh tế) do có hệ số điểm nhân tố nhỏ nhất 0,391 .

- Nhóm nhân tố XH có phương trình:

$$
\begin{aligned}
& \mathrm{XH}=0,309 \mathrm{XH} 1+0,321 \mathrm{XH} 2+0,332 \mathrm{XH} 3+ \\
& 0,320 \mathrm{XH} 4
\end{aligned}
$$

Nhóm nhân tố XH chịu ảnh hưởng bởi 4 biến quan sát (đặc điểm nhân khẩu học của cư dân (dân số, trình độ dân trí, sinh kế, thu nhập), sự đồng thuận xã hội, tốc độ đô thị hóa, văn hóa - lịch sử, phong tục, tập quán). Trong đó, nhóm yếu tố XH chịu ảnh hưởng mạnh nhất bởi biến XH3 (tốc độ đô thị hóa) do có hệ số điểm nhân tố lớn nhất 0,332 và chịu ảnh hưởng ít nhất bởi biến XH1 (đặc điểm nhân khẩu học của cư dân) do có hệ số điểm nhân tố nhỏ nhất 0,309 .

- Nhóm nhân tố MT có phương trình:

$$
\mathrm{MT}=0,401 \mathrm{MT} 1+0,405 \mathrm{MT} 2+0,377 \mathrm{MT} 3
$$

Nhóm nhân tố MT chịu ảnh hưởng bởi 3 biến quan sát (điều kiện tự nhiên (khí hậu, môi trường, tài nguyên, khoáng sản), vị trí địa lý và biến đổi khí hậu). Trong đó, nhóm yếu tố MT chịu ảnh hưởng mạnh nhất bởi biến MT2 (vị trí địa lý) do có hệ số điểm nhân tố lớn nhất 0,405 và chịu ảnh hưởng ít nhất bởi biến MT3 (biến đổi khí hậu) do có hệ số điểm nhân tố nhỏ nhất 0,377 .

- Nhóm nhân tố PL có phương trình:
$\mathrm{PL}=0,329 \mathrm{PL} 1+0,318 \mathrm{PL} 2+0,315 \mathrm{PL} 3+$ 0,295PL4

Nhóm nhân tố PL chịu ảnh hưởng bởi 4 biến quan sát (các quy định của pháp luật về quy hoạch sử dụng đất, công tác kiểm tra, giám sát việc triển khai thực hiện quy hoạch đã được phê duyệt, sự đồng bộ giữa các quy hoạch, các quy định, tiêu chí về bảo vệ môi trường và phát triển bền vững trong công tác quy hoạch sử dụng đất). Trong đó, nhóm yếu tố PL chịu ảnh hưởng mạnh nhất bởi biến PL1 (các quy định của pháp luật về quy hoạch sử dụng đất) do có hệ số điểm nhân tố lớn nhất 0,329 và chịu ảnh hưởng ít nhất bởi biến PL4 (các quy định, tiêu chí về bảo vệ môi trường và phát triển bền vững trong công tác quy hoạch sử dụng đất) do có hệ số điểm nhân tố nhỏ nhất 0,295 .

- Nhóm nhân tố $\mathrm{K}$ có phương trình:

$$
\mathrm{K}=0,401 \mathrm{~K} 1+0,394 \mathrm{~K} 2+0,343 \mathrm{~K} 3
$$

Nhóm nhân tố khác $(\mathrm{K})$ chịu ảnh hưởng bởi 3 biến quan sát (năng lực cán bộ (cán bộ tham mưu, cán bộ lãnh đạo, quản lý) phục vụ công tác quy hoạch sử dụng đất, tầm nhìn và định hướng phát triển, kinh nghiệm và sự kế thừa từ các kỳ quy hoạch trước). Trong đó, nhóm yếu tố $\mathrm{K}$ chịu ảnh hưởng mạnh nhất bởi biến K1 (năng lực cán bộ (cán bộ tham mưu, cán bộ lãnh đạo, quản lý) phục vụ công tác quy hoạch sử dụng đất) do có hệ số điểm nhân tố lớn nhất 0,401 và chịu ảnh hưởng ít nhất bởi biến K3 (kinh nghiệm và sự kế thừa từ các kỳ quy hoạch trước) do có hệ số điểm nhân tố nhỏ nhất 0,342 .

\subsubsection{Các nhân tố ảnh hưởng đến quy hoạch sư dụng đất đai}

Nghiên cứu sử dụng mô hình hồi quy đa biến để xác định hệ số mức độ ảnh hưởng của các yếu tố chính đối với quy hoạch sử dụng đất đai. Kết quả phân tích mô hình hồi quy đa biến được trình bày ở Bảng 6.

\section{Bảng 6. Các nhân tố ảnh hưởng đến quy hoạch sử dụng đất đai}

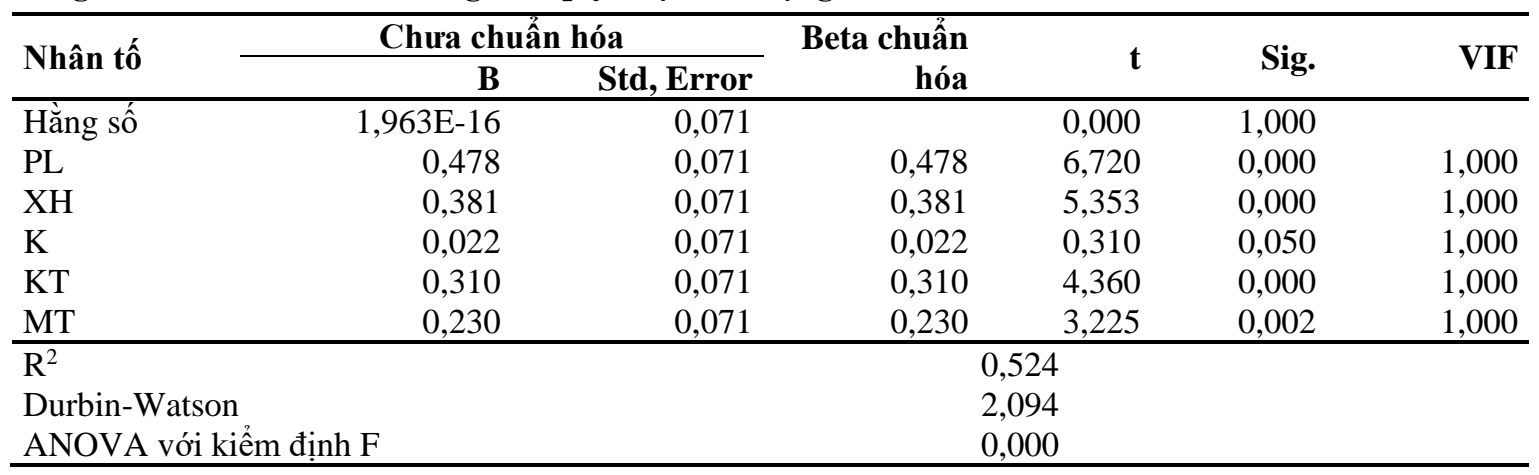


Qua Bảng 6, hệ số $\mathrm{R}^{2}=0,524$ có nghĩa là mô hình có thể giải thích được $52,4 \%$ cho tổng thể về mối quan hệ giữa quy hoạch sử dụng đất đai và các nhân tố được đưa ra theo quan điểm của cán bộ quản lý. Kết quả kiểm định Durbin-Watson cho trị số bằng 2,094 gần với hệ số 2,0 và trong khoảng từ 1 3 chứng tỏ không có tương quan chuỗi bậc 1 trong mô hình (Hoàng Trọng \& Chu Nguyễn Mộng Ngọc, 2008). Kết quả phân tích ANOVA với kiểm định $\mathrm{F}$ sử dụng trong bảng phân tích phương sai là phép kiểm định giả thuyết về độ phù hợp của mô hình hồi quy tuyến tính. Kết quả cho thấy giá trị Sig. $=0,000$ nên mô hình hồi quy tuyến tính đã xây dựng là phù hợp, mô hình hồi quy đưa ra tương đối phù hợp với mức ý nghĩa $1,0 \%$.

Kết quả nghiên cứu cho thấy các nhân tố đều có hệ số hồi quy $\beta>0$ nên các nhân tố này có ảnh hưởng cùng chiều với quy hoạch sử dụng đất đai. Dựa trên mức ý nghĩa (sig.) của từng nhân tố, cả 5 nhân tố có tác động lên quy hoạch sử dụng đất đai theo đánh giá của cán bộ quản lý có đất trong vùng quy hoạch đó là nhóm biến $\mathrm{KT}, \mathrm{XH}, \mathrm{MT}, \mathrm{PL}$ với mức ý nghĩa thống kê là $1 \%$ và nhóm $\mathrm{K}$ với mức ý nghĩa thống kê $5 \%$.

Mô hình nghiên cứu được viết lại như sau:

$\mathrm{QHSD}=0,478 \cdot \mathrm{PL}+0,381 \cdot \mathrm{XH}+0,220 . \mathrm{K}+$ $0,310 . \mathrm{KT}+0,230 . \mathrm{MT}$

Biểu đồ trọng số yếu tố ảnh hưởng quy hoạch sử dụng đất đai thành phố Cần Thơ dưới góc nhìn cán bộ quản lý (Hình 1).

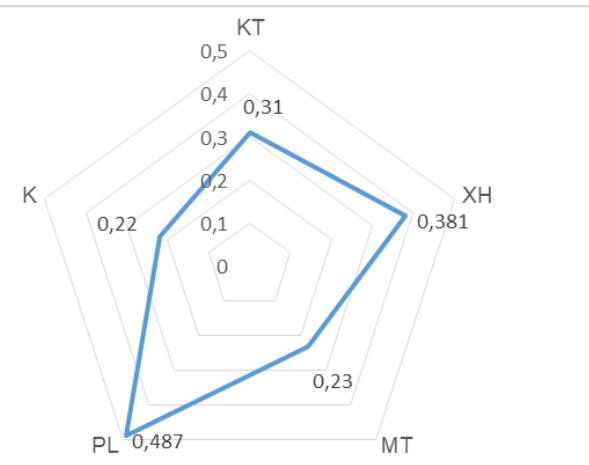

\section{Hình 1. Biểu đồ trọng số yếu tố ảnh hưởng quy hoạch sử dụng đất đai thành phố Cần Thơ theo góc nhìn nhà quản lý, cán bộ chuyên môn}

Đối với nhà quản lý, cán bộ chuyên môn, các nhóm nhân tố được đưa ra đều có tác động thuận chiều lên quy hoạch sử dụng đất đai (hệ số $\beta>0$ ). Qua Hình 1, yếu tố ảnh hưởng mạnh nhất là nhóm yếu tố PL (hệ số $\beta=0,478$ ), thứ 2 là XH (hệ số $\beta=$ 0,381 ), thứ 3 là $\mathrm{KT}$ (hệ số $\beta=0,310$ ), thứ 4 là $\mathrm{MT}$ (hệ số $\beta=0,230$ ), cuối cùng là nhóm yếu tố $K$ (hệ số $\beta=0,220)$.

\section{GIẢI PHÁP CHO QUY HOẠCH SỬ DỤNG ĐẤT KHẢ THI VÀ HIỆU QUẢ}

Kết quả nghiên cứu đã chỉ ra ở góc nhìn của nhà quản lý, cán bộ chuyên môn có sự khác biệt so với người dân khi nhóm yếu tố PL (gồm các quy định của pháp luật về quy hoạch sử dụng đất, công tác kiểm tra, giám sát việc triển khai thực hiện quy hoạch đã được phê duyệt, sự đồng bộ giữa các quy hoạch, các quy định, tiêu chí về bảo vệ môi trường và phát triển bền vững trong công tác quy hoạch sử dụng đất) có ảnh hưởng mạnh hơn những yếu tố khác. Đồng thời đối với góc nhìn nhà quản lý, cán bộ chuyên môn, yếu tố tốc độ đô thị hóa ảnh hưởng mạnh nhất trong nhóm yếu tố xã hội (gồm đặc điểm dân cư, sự đồng thuận xã hội, tốc độ đô thị hóa, văn hóa - lịch sử, phong tục, tập quán). Trong nhóm yếu tố KT (gồm nguồn kinh phí chi cho quy hoạch sử dụng đất, tăng trưởng kinh tế, cơ cấu kinh tế) cũng có ảnh hưởng đối với quy hoạch sử dụng đất thành phố Cần Thơ. Đây là nhóm yếu tố có ảnh hưởng cùng chiều mạnh thứ 3 đến quy hoạch sử dụng đất đai thành phố Cần Thơ theo đánh giá của nhà quản lý, có nghĩa là khi kinh tế tăng trưởng, cơ cấu kinh tế hợp lý và nguồn kinh phí đầu tư chi cho quy hoạch nhiều thì góp phần cho quy hoạch sử dụng đất đai sẽ được thực hiện hiệu quả.

Một số giải pháp, kiến nghị được đề xuất như sau:

- Cần rà soát, tổ chức lập quy hoạch sử dụng đất thành phố Cần Thơ giai đoạn 2020 - 2030, kế hoạch sử dụng đất 05 năm kỳ đầu 2020 - 2025 phù hợp quy hoạch, kế hoạch sử dụng đất cấp quốc gia. Việc triển khai lập quy hoạch, kế hoạch sử dụng đất các cấp theo quy định của Luật Quy hoạch, Luật đất đai. Chính sách về quy hoạch sử dụng đất đai nên đổi mới theo hướng tích hợp, hiệu quả, bền vững.

- Cần nghiên cứu đặc điểm dân cư, văn hóa lịch sử, phong tục tập quán, sự đồng thuận xã hội, tốc độ đô thị hóa khi lập quy hoạch sử dụng đất; trong đó, chú trọng tốc độ đô thị hóa để dự báo nhu cầu sử dụng đất trong quá trình lập quy hoạch.

- Cần đánh giá về tăng trưởng kinh tế và cơ cấu kinh tế để định hướng việc phân bổ chỉ tiêu sử dụng đất các ngành lĩnh vực; quan tâm nguồn kinh phí đầu tư chi cho việc lập quy hoạch, kinh phí thực hiện quy hoạch thông qua dự án kêu gọi đầu tư. Nhà quản lý 
cần công bố danh mục dự án kêu gọi đầu tư cùng với việc công khai quy hoạch sử dụng đất.

- Thường xuyên tổ chức thanh tra, kiểm tra việc chấp hành các quy định của pháp luật liên quan đến quy hoạch sử dụng đất đai để kịp thời xử lý và chấn chỉnh; rà soát các quy hoạch, kế hoạch sử dụng đất đã quá thời hạn thực hiện, có biện pháp xử lý dứt điểm để bảo đảm quyền lợi của người sử dụng đất.

\section{KẾT LUẬN}

Nghiên cứu đã ứng dụng phân tích nhân tố khám phá EFA và xác định được 5 nhóm yếu tố ảnh hưởng đến quy hoạch sử dụng đất thành phố Cần Thơ, bao gồm nhóm KT, MT, XH, PL và nhóm yếu tố K. Kết quả phân tích của mô hình hồi quy tuyến tính đa biến cho thấy quy hoạch sử dụng đất ở thành phố Cần Thơ được giải thích bởi $52,4 \%$ sự biến động của 5 nhóm biến độc lập. Trong đó, nhóm nhân tố PL ảnh hưởng nhiều nhất với đóng góp $47,8 \%$, thứ hai là nhóm XH với đóng góp $38,1 \%$, thứ ba là nhóm yếu tố KT với đóng góp $31 \%$ so với các yếu tố còn lại.

Kết quả nghiên cứu đã chỉ ra việc sử dụng đất trong phân kỳ thực hiện quy hoạch sử dụng đất tại thành phố Cần Thơ giai đoạn 2010-2020 chưa đạt theo kế hoạch đề ra và đề xuất bốn giải pháp trong quản lý quy hoạch sử dụng đất. Trong thời gian tới, để quy hoạch sử dụng đất ở thành phố Cần Thơ ngày một hiệu quả, nhà quản lý cần quan tâm: (i) việc hoàn thiện các quy định của pháp luật về quy hoạch sử dụng đất, (ii) tốc độ đô thị hóa để dự báo nhu cầu sử dụng đất trong quá trình lập quy hoạch, (iii) kinh phí lập, điều tra, khảo sát, thực hiện quy hoạch trong việc quy hoạch sử dụng đất đai, (iv) đào tạo cán bộ làm công tác quy hoạch.

\section{TÀI LIỆU THAM KHẢO}

Bliss, C. I. (1934). The method of probits. Science, 79(2), 38-39.

Bộ Chính trị. (2020). Nghị quyết số 59-NQ/TW ngày 05/8/2020 về xây dưng và phát triển thành phố Cần Tho đến nắm 2030, tầm nhìn đến năm 2045.
Cronbach L. (1951). Coefficient alpha and the internal structure of tests. Psychomerika. 16, 297-334.

Chính phủ. (2013). Nghị quyết số 57-NQ/CP ngày 04/5/2013 về quy hoạch sử dụng đất đến năm 2020 và kế hoạch sủ dụng đất 05 năm kỳ đầu (2011-2015) của thành phố Cần Tho:

Chính phủ. (2018). Nghị quyết số 52-NQ/CP ngày 10/5/2018 về điều chỉnh quy hoạch sủ dụng đất đến năm 2020 và kế hoạch sử dụng đất 05 năm kỳ cuối (2016-2020) của thành phố Cần Tho.

Hair, Jr. J. F., Anderson, R. E., Tatham R. L. \& Black W. C. (1998). Multivariate Data Analysis (5th ed.). New York: Macmillan Publishing Company.

Hair, J. F., Black, W.C., Babin, B.J., Anderson. RE. \& Tatham, RL. (2006). Multivariate data analysis (6th ed.). Upper Saddle River, NJ: Pearson University Press.

Hoàng Trọng \& Chu Nguyễn Mộng Ngọc. (2005). Phân tích dũ liệu nghiên cúu với SPSS. Nhà xuất bản Thống kê.

Likert, R. A. (1932). A technique for measurements a attitudes, Archives of Psychology.

Lê Anh Tuấn \& Võ Quang Minh. (2015). Phân tích những yếu tố ảnh hưởng đến thưc hiện quy hoạch, kế hoạch sử dụng đất thành phố Cần Thơ dưới sự hỗ trợ của GIS. Kỷ yếu hội nghị GIS toàn quốc 2015, Hà Nội, Việt Nam, 643-467. https://sj.ctu.edu.vn/ql/docgia/kyyeuhoinghitrong nuoc-2015/baibao-30971.html?page_current=5

Nunnally, J. C., \& Bernstein, I. H. (1994). Psychometric theory (3rd ed.). New York: McGraw-Hill.

Streiner, D. L (2003). Starting at the beginning: an introduction to coefficient alpha and internal consistency. Journal of personality assessment, 80(1), 99-103.

Sở Tài nguyên và Môi trường thành phố Cần Thơ. (2020). Báo cáo kết quả thưc hiện quy hoạch sủ dụng đất 2010-2020 (Số 59/BC-STNMT). 